\title{
Antioxidant properties of candy caramel with plant extracts
}

\author{
Liubov Mazur ${ }^{1}$, Sergii Gubsky², \\ Antonella Dorohovych ${ }^{1}$, Maksym Labazov ${ }^{2}$
}

\author{
1 - National University of Food Technologies, Kyiv, Ukraine \\ 2 - Kharkiv State University of Food Technology and Trade, Kharkiv, Ukraine
}

\section{Keywords:}

Caramel

Antioxidant

Polyphenolic

Ascorbic acid

Coulometry

Article history:

Received 21.01.2018

Received in revised

form 27.02.2018

Accepted 29.03.2018

Corresponding

author:

Liubov Mazur

E-mail:

Liubovmazur@ukr.net

DOI: $10.24263 / 2304-$ 974X-2018-7-1-3

\section{Abstract}

Introduction. An investigation of the antioxidant properties of the candy caramel samples based on the sugar replacers of maltitol and isomaltol, enriched with ascorbic acid and biologically active substances of water extracts of dried leaves of Menthae Piperitae and flowers of Matricariae chamomilla L. was carried out.

Materials and methods. The total antioxidant capacity (TAC) and total content of polyphenolic compounds (TPC) of candy caramel samples were determined by galvanostatic coulometric titration with electrogenated bromine and by spectrophotometry using the Folin-Ciocalteu reagent. The results were expressed as milligrams of gallic (GAE) or ascorbic (AAE) acids per gram of the sample (SW). The amount of ascorbic acid in the final product was determined by galvanostatic coulometry with electrogenerated iodine.

Results and discussion. The total antioxidant capacity of the aqueous extracts of of Menthae piperitae and flowers of Matricariae chamomilla L. was 40.0 and $23.3 \mathrm{mg}$ of GAE / g SW, respectively, and the total content of polyphenols was 54.5 and 17.1 GAE / g SW.

It is shown that samples of candy caramel based on sugar substitutes with the addition of plant extracts contain from 48 to $66 \%$ of the initial mass of ascorbic acid.

Based on the experimental data of the caramel samples with the variation of the recipe ingredients, the correct values of the total polyphenol content for the two candy caramel samples in the presence of interfering compounds were determined that are $408 \mathrm{mg} \mathrm{GAE} / 100 \mathrm{~g}$ of the sample for caramel based on maltitol and Matricariae chamomilla L. extract and $222 \mathrm{mg} \mathrm{GAE} / 100 \mathrm{~g}$ sample for caramel based on isomaltol and Menthae piperitae extract.

A positive correlation between the values of the total antioxidant capacity of TAC and the total content of polyphenols TPC for the samples was obtained.

Conclusions. The obtained results indicate the prospects of technologies for enriching the candy caramel on sugar replacers with natural biologically active substances with antioxidant properties for the production of diet-functional food systems. 


\section{Introduction}

Confectionery products can not be attributed to healthy eating foods, because they have a low nutritional value. Among the wide range of confectionery products, candy caramel is in great demand among the Ukrainian population, especially in children, due to high organoleptic indicators and low price. Due to these factors, the volume of its production increases with each passing year. Almost all types of candy caramel, which are offered by a modern production, have no functional ingredients. The main raw material during the production of candy caramel is white crystalline sugar and caramel molasses, the glycemic index of which is quite high, therefore, candy caramel which is made according to the traditional technology cannot be consumed by patients with diabetes mellitus.

There is a need for the use of sugar substitutes of the new generation to reduce the glycemic index of candy caramel - polyols (isomaltitol, maltitol, eritritol, lactitol) that have lower caloric content in comparison with sugar, lower glycemic index, have prebiotic properties and causing no tooth decay, especially isomaltitol and maltitol $[1,2]$.

Among these polyols, known in the Ukrainian market is isomaltitol and maltitol. Isomaltitol has a fairly low hygroscopicity, and because of this you can significantly extend the term of storage of caramel products. Isomaltitol doesn't have any harmful effects on the teeth, since it causing no caries, doesn't increase glucose and insulin levels in the blood, and has a reduced caloric content. Maltitol is a polyol obtained by means of hydrolysis of maltose, has anti-crystalline properties. Important for the usage in food technologies, physicochemical and other characteristics of these substances are given in the Table 1.

\section{Parameters of polyols}

Table 1

\begin{tabular}{|c|c|c|c|c|c|}
\hline Polyol & $\begin{array}{c}\text { Sweetenary, } \\
\text { unit }\end{array}$ & $\begin{array}{c}\text { Energy, } \\
\mathbf{k c a l} / \mathbf{g}\end{array}$ & $\begin{array}{c}\text { Glycemic } \\
\text { index, } \\
\mathbf{\%}\end{array}$ & $\begin{array}{c}\text { Melting } \\
\text { point, } \\
{ }^{\circ} \mathbf{C}\end{array}$ & $\begin{array}{c}\text { Solubility in } \\
\text { water }(\mathbf{2 0} \\
\mathbf{\%}\end{array}$ \\
\hline ' $\mathbf{C})$, \\
\hline Isomaltitol & $0.5-0.6$ & 2.4 & $9 \pm 3$ & $142-150$ & 24.5 \\
\hline Maltitol & 0.9 & 2.4 & 36 & $144-152$ & 65.0 \\
\hline
\end{tabular}

Technologies of caramel production using maltitol and isomaltitol are used in world practice, but such products contain high-glucose molasses or artificial sweeteners [3,4].

Antioxidants are important components of a healthy nutrition due to their ability to block a harmful effect on the human body of free radicals. These substances are essential components of all tissues and cells of living organisms. That is why their usage in the technologies of production of functional food products is a modern trend of the food industry development. According to the abstract and citation database Web of Science Core Collection, the number of publications devoted to the research of antioxidant activity of food systems has increased over the course of 20 years in an exponential relation. Thus, the number of sources which have in their title, in the abstract or in the keywords a combination of words "food\&antioxidant" reaches about 25307.

In recent years, interest in the antioxidant properties of substances of natural origin has grown [5]. This is due to the fact that the best sources of antioxidants are plants, in particular medicinal ones, which contain them in the form of related compounds complexes [6]. These complexes include phenolic compounds (flavonoids, isoflavonoids, tannins, etc.), vitamins (C, E, A), carotenoids [7, 8], which are able to prevent free radical oxidation 
of biological structures of the organism, slowing down aging processes and development of pathological changes.

The usage of plant extracts in confectionery products technologies is not a new practice. However, the technology of full replacement of water on the aqueous extract is a new and interesting solution in the enrichment of candy caramel [9].

In this study, water extracts of chamomile and peppermint were preferred, the chemical composition of which is quite rich in the presence of antioxidants, and the extracts have satisfactory organoleptic indicators. Dried Matricaria chamomilla L. flowers (MCF) are traditionally used in medical practice. From a pharmacological point of view, this product is a selective inhibitor of COX-2 with anti-inflammatory activity [10], demonstrates antimicrobial, antioxidant, antiplatelet and chemopreventive effects [11, 12]. The antioxidant effect of MCF is associated with the content of essential oil (not less than $0.3 \%$ ), which includes chamazulene, prochamazulene, other terpenes and sesquiterpenes [13], as well as the presence of polyphenolic compounds $[14,15]$.

Menthae piperitae folia (MPF) contains essential oil (2-3\%), which includes menthol, pinene, limonene, felandren, cineol and other terpenoids. In addition, flavonoids, ursolic and oleanolic acids, betaine, carotene, hesperidin, tannin substances, organic acids, trace elements can be found in the mint leaves [6]. According to [16-21], extracts of MP demonstrate analgesic, antibacterial, antiviral, choleretic and antinociceptive activity, antioxidant and antiallergic effects.

Among natural antioxidants the most common is ascorbic acid (AA), which can not only prevents free radical oxidation, but also takes part in the synthesis of collagen, promotes adsorption of iron and excretion of cholesterol [22].

Thus, the developed technology of candy caramel on the basis of sugar substitutes with the adding of ascorbic acid and extracts of MPF or MFC allow to provide in this product dietary and functional properties. Among the latest, the most important are antioxidant properties, the results in the researches of which are the purpose of this publication.

\section{Materials and methods}

\section{Materials}

The following chemicals used in this study are as follows: potassium bromide, potassium iodide, sodium hydroxide, sodium carbonate (Reachim, Russia); Sulphur acid and hydrochloric acid (Sumychimprom, Ukraine); gallic acid (Sigma Aldrich, USA); ascorbic acid (China). All the chemicals used in this experiment were of analytical grade, except for ascorbic acid, which were of pharmaceutical grade (British Pharmacopeia).

For manufacture of the candy caramel isomaltitol (Isodeco, Italy), maltitol (Intenson, Poland) and fructose (Vitamin, Ukraine) was used.

The synthesis of Folin-Ciocalteu reagent was done according to the procedure [23]. All the chemicals used in this procedure were of analytical grade. For analysis $2 \mathrm{M}$ solution was used.

For preparation of the solutions distilled water with electric conductivity no more 0.55 $\mathrm{mS} / \mathrm{m}$ was used. 


\section{Preparation of Menthae piperitae folia and Matricaria chamomilla L. flores extracts}

Dried samples of Menthae piperitae folia and Matricariae chamomilla L. flores (Liktravi, Ukraine) were purchased from the local pharmacy.

During the experiment, it was found that the liquid-solid phase extraction for the ratio of dried plant material (Menthae piperitae folia or Matricariae chamomilla L. flores) to the solvent mass (water) (S/L) 1:10 has a maximum yield.

For process of extraction important parameter is the particle size of the raw material. It was established that the maximum yield of soluble solids during extraction was obtained for the particle size of 1-3 mm.

When investigating the effect of temperature and duration of extraction, experimental data were obtained at room temperature and in thermostat conditions. Additional studies have shown that the best transition of dry matter occurs during heat treatment near $100^{\circ} \mathrm{C}$ $\left(97-98^{\circ} \mathrm{C}\right)$ for $12-15$ minutes and subsequent storage of the extract for $120-150$ minutes in room conditions.

Thus, the exact weighting of the crushed powder of the sample $(10.0 \mathrm{~g})$ was boiled from $100 \mathrm{ml}$ of water for $12-15 \mathrm{~min}$. Subsequently, extractions were performed by maceration for 120-150 min at room temperature. The mixture was filtered using a paper filter. The content of soluble solid in the finished extracts did not exceed $5^{\circ} \mathrm{Bx}$.

The extracts obtained were used to produce caramel, as well as to study their antioxidant capacity and the content of polyphenolic compounds. Between the experiments, samples were stored in a frozen state at $-18^{\circ} \mathrm{C}$.

\section{Manufacture of candy caramel with plant extract} follows:

Candy caramel was produced by innovative technology, the features of which were as

- it was proposed to completely replace the water with extracts of plant material (Menthae piperitae folia or Matricariae chamomilla L. flores), taking into account the amount of soluble solids of the extract;

- a mixture of isomaltol-fructose $(85: 15, \mathrm{w} / \mathrm{w})$ and maltitol-fructose $(90: 10, \mathrm{w} / \mathrm{w})$ was used;

- mass fractions of Menthae piperitae folia and Matricariae chamomilla L. flores extracts in the caramel content were respectively $30 \%$ and $10 \%$ by weight of the sugar substitute-fructose mixture;

- $\quad$ the so obtained syrup was added to the content of soluble solids $98^{\circ} \mathrm{Bx}$;

- to provide candy caramel the necessary organoleptic properties and increase the antioxidant activity at the stage of cooling the caramel mass at a temperature of $80-85$ ${ }^{\circ} \mathrm{C}$ was added to the caramel ascorbic acid in the amount of $2 \%$ to the mass of samples.

\section{Preparation of caramels aqueous solutions}

Determination of antioxidant properties of caramel with the addition of plant extracts was carried out using aqueous solutions. From five to eight grams of candy caramel was accurately weighed and was triturated in a porcelain mortar with 10-20 ml of water. Then transferred quantitatively to a pre-weighed conical flask. After addition of distilled water in a ratio $1: 10(\mathrm{w} / \mathrm{w})$ and weighed the solution. 
The effect of the caramel's components on its the antioxidant properties was studied using the following eight types of candy caramel samples (Table 2).

Table 2

Candy caramel samples

\begin{tabular}{|c|c|c|c|}
\hline \multirow{2}{*}{$\begin{array}{c}\text { Abbreviation of } \\
\text { sample }\end{array}$} & \multicolumn{3}{|c|}{ Basic compounds of samples } \\
\hline & Sugar substitutes & Extract & Ascorbic acid \\
\hline $\mathrm{K} 1$ & \multirow{4}{*}{ maltitol } & - & - \\
\hline $\mathrm{K} 2$ & & $\begin{array}{l}\text { Matricaria chamomilla } L . \\
\text { flores }\end{array}$ & - \\
\hline K3 & & - & present \\
\hline $\mathrm{K} 4$ & & $\begin{array}{l}\text { Matricaria chamomilla } L . \\
\text { flores }\end{array}$ & present \\
\hline K5 & \multirow{4}{*}{ isomaltitol } & - & - \\
\hline K6 & & Menthae piperitae folia & - \\
\hline K7 & & - & present \\
\hline K8 & & Menthae piperitae folia & present \\
\hline
\end{tabular}

\section{Determination of physico-chemical parameters}

The electric conductivity was measured by conductometer CEL-1M2 (Analitpribor, Georgia). Total soluble solids based on the degree of brix $\left({ }^{\circ} \mathrm{Bx}\right)$ was by using a refractometer URL (Avtomatika, Armenia) according [24].

The $\mathrm{pH}$ and temperature of solutions was determined by $692 \mathrm{pH} / \mathrm{Ion}$ Meter (Metrohm, Swizz) with Combined LL pH glass electrode with Pt 1000 temperature sensor (Metroohm, Swizz).

If necessary, the solutions were kept at a constant temperature using the thermostat 1TZH-0.03 (Russia). The temperature in this device was maintained at an accuracy of 0.2 ${ }^{\circ} \mathrm{C}$ and determined by the sensor SM60-Pt1000 (Yokogawa Europa, Holland) with a precision of $0.1^{\circ} \mathrm{C}$.

The samples were weighed on laboratory scales balance CBA-300-0.005 (T-Scale, China) with accuracy of $5 \mathrm{mg}$ and on analytical laboratory scales balance VLR-200 (Gosmetr, Russia) with accuracy up to $0.1 \mathrm{mg}$.

\section{Determination of Ascorbic Acid}

The amount of ascorbic acid in solutions of caramel samples was determined by the coulometry with electrogenerated iodine [25]. The electrogeneration of iodine was performed using a PU-1 (ZIP, Belarus) potentiostat in a $0.1 \mathrm{M}$ solution of $\mathrm{KI}$ in an phthalate buffer solution ( $\mathrm{pH}=4,01)$, this was performed on a platinum electrode SM29-PT9 (Yokogawa Europa, Holland) under a constant current of 2.0-5.0 mA.

The end 7 point of titration was established a potentiometric method with two platinum EPV-1 (ZIP, Belarus) and silver chloride EVL-1M3.1 (ZIP, Belarus) electrodes.

Monitoring and experimental data recording (electromotive force-time) was performed electronically with the help of PhCh Data logger device (Arduino Uno microcontroller with 
ADS1115 16-bit analog-to-digital converter and automatic timer relay) and $\mathrm{PhCh}$ Graph software.

Validation of method for the determination of AA was carried out according to [26].

The concentration of AA m (mg/100g sample) in candy caramels was established by the equation:

$$
m=\frac{100 I t M}{n F m_{a l}}
$$

where $I$ is current strength, $t$ is the time of the titration end-point, $M$ is the molar weight of AA, $F$ is Faraday's constant $96500 \mathrm{C} /$ mole, $n$ is the number of electrons, participating in the reaction, $m_{a l}$ is the weight of the aliquot portion of the solution.

\section{Determination of the Total Antioxidant Capacity}

TAC of simples was determined by the reaction with electronegative bromine as [26, 27] using the same method that was detailed for ascorbic acid. The experimental data of coulometric titration were used to calculate the TAC(q) as the electricity quantity Q, spent for titration per $100 \mathrm{~g}$ of the sample and it were calculated by expression:

$$
\operatorname{TAC}(q)=\frac{100 \mathrm{Itm}_{\text {sol }}}{m_{a l} m_{\text {sam }}}
$$

where $m_{\text {sam }}$ is the weight of the sample (dry powder of plant or candy caramel), $m_{\text {sol }}$ is the total weight of the solution for candy caramel or of the extract for powder of plant.

The total antioxidant capacity (3) is expressed in units of ascorbic acid, recalculated per 100 $\mathrm{g}$ of sample. Values of TAC in ascorbic acid equivalent (mg AAE/100 g sample) were calculated by expression:

$$
T A C=\frac{T A C(q)-a}{b}
$$

where $\mathrm{a}$ and $\mathrm{b}$ are parameters of linear regression $\mathrm{Y}=\mathrm{a}+\mathrm{bX}$ on series working standard solutions of ascorbic acid or gallic acids in water. [28].

For aqueous solutions of AA the coefficients of the linear regression were determined in

To calculate the experimental values of TAC in the equivalent of the mass of gallic acid (GA) as a reference, a coulometric titration of standard aqueous solutions of gallic acid at a concentration of $10-1000 \mu \mathrm{g} / \mathrm{g}$ by electrogenerated bromine was conducted as a reference (Table $3)$. 
Linear regressions $\mathbf{Y}=\mathbf{a}+\mathbf{b} \cdot \mathbf{X}$ on series working standard solutions of gallic acid in water (coulometry)

\begin{tabular}{|l|c|}
\hline \multicolumn{1}{|c|}{ Regression parameters } & Data \\
\hline Range, $\mathrm{mg} / \mathrm{kg}$ & $10-1000$ \\
\hline Regression equation: & $Y=a+b X$ \\
\hline Slope, $b$ & 2.2693 \\
\hline Intercept, $a$ & 0.2567 \\
\hline Regression coefficient, $r$ & 0.9998 \\
\hline Standard deviation of the analytical signal, $\sigma$ & 1.269 \\
\hline Limit of detection, $\mathrm{mg} / \mathrm{kg}$ & 1.8 \\
\hline Limit of quantitation, $\mathrm{mg} / \mathrm{kg}$ & 5.6 \\
\hline
\end{tabular}

The obtained dependence is linear with a high coefficient of correlation of 0.9998 and an slope of the curve of 2.2693 , which, with an accuracy of $0.18 \%$, corresponds to the theoretical value of 2,2686 for gallic acid according to the Faraday law.

\section{Determination of the Total Phenolic Content}

The concentration of phenolic compounds in samples was estimated using a modified spectrophotometric Folin-Ciocalteu method according Singleton and Rossi [29] with the transition from volume to weight of the aliquot portion. Briefly, $0.1 \mathrm{~g}$ of extract, standard or blank solution was mixed with $0.5 \mathrm{~g}$ of Folin-Ciocalteu's reagent and $2 \mathrm{~g}$ water. A sample of extracts was previously diluted in 10 times. After $8 \mathrm{~min}, 1.5 \mathrm{~g}$ of sodium carbonate $20 \%$ $(\mathrm{w} / \mathrm{w})$ solution was added to the mixture and adjusted to $10 \mathrm{~g}$ with distilled water. Mixture was incubated for $30 \mathrm{~min}$ in thermostat at $45^{\circ} \mathrm{C}$ temperature. Finally, measurement of absorbance was carried out in spectrophotometer SF-46 (Lomo, Russia) at wavelength of $765 \mathrm{~nm}$ against a blank sample.

Gallic acid was used as a standard. The TPC values were expressed as mg of gallic acid equivalents (GAEs) per g of dry weight (SW) of plant. A $1000 \mathrm{mg} / \mathrm{kg}$ stock solution of gallic acid was prepared by dissolving $0.1 \mathrm{~g}$ of gallic acid in $100 \mathrm{~g}$ of distilled water. Working standard solutions of gallic acid at five different concentration levels $(25,50,100$, 250 , and $500 \mathrm{mg} / \mathrm{kg}$ ) were prepared by dilution of the stock solution.

The gallic acid calibration curve was constructed in the range of $25-500 \mathrm{mg} / \mathrm{kg}$ and used to calculate linear regression models (Table 4).

\section{Statistical analysis}

One-way analysis of variance (ANOVA) was carried out on the experimental results. Determination of the experimental values were done for a number of parallel measurements $(n=4)$. The difference of parameters were tested by Student's t-test. A $p<0.05$ was considered as statistically significant. All results were presented as mean value \pm confidence interval. The data was analyzed by using OriginPro v.8 (OriginLab Corp., USA) statistical software. 
Table 4

Linear regressions $\mathrm{Y}=\mathbf{a}+\mathbf{b} \cdot \mathbf{X}$ on series working standard solutions of gallic acid in water (The Folin-Ciocalteu method)

\begin{tabular}{|l|c|}
\hline \multicolumn{1}{|c|}{ Regression parameters } & Data \\
\hline Range, $\mathrm{mg} / \mathrm{kg}$ & $25-500$ \\
\hline Regression equation: & $Y=a+b X$ \\
\hline Slope, $b$ & 0.00104 \\
\hline Intercept, $a$ & -0.00262 \\
\hline Regression coefficient, $r$ & 0.9993 \\
\hline Standard deviation of the analytical signal, $\sigma$ & 0.0031 \\
\hline Limit of detection, $\mathrm{mg} / \mathrm{kg}$ & 0.25 \\
\hline Limit of quantitation, $\mathrm{mg} / \mathrm{kg}$ & 0.76 \\
\hline
\end{tabular}

\section{Results and discussion}

\section{Ascorbic acid amount in candy caramel simples}

Table 5 shows us experimental data on the amount of ascorbic acid in candy caramel samples.

According to the technological process, $2000 \mathrm{mg}$ of ascorbic acid were added to the samples at the stage of cooling the caramel mass at a temperature of about $40{ }^{\circ} \mathrm{C}$. For comparative analysis, samples of caramel with ascorbic acid and with the addition $(\mathrm{K} 4, \mathrm{~K} 8)$ or without addition $(\mathrm{K} 3, \mathrm{~K} 7)$ of chamomile and mint extracts were prepared.

According to the data on the Table 4, despite the usage in the technological process of the manufacturing of high-temperature caramel, there are about $50 \%$ of the initial number of ascorbic acid remained in samples.

Table 5

Ascorbic acid amount in candy caramel samples $(n=4, P=0.95)$

\begin{tabular}{|c|c|c|c|c|}
\hline Sample & $\begin{array}{c}\text { Added according } \\
\text { recipe, } \\
\text { mg }\end{array}$ & $\begin{array}{c}\text { Founded in } \\
\text { experiment, } \\
\text { mg }\end{array}$ & $\begin{array}{c}\text { RSD, } \\
\mathbf{\%}\end{array}$ & $\begin{array}{c}\text { Residue } \\
\text { amount, } \\
\mathbf{\%}\end{array}$ \\
\hline K3 & 2000 & $1179 \pm 15$ & 1.7 & $59.0 \%$ \\
\hline K4 & 2000 & $1100 \pm 13$ & 2.0 & $55.0 \%$ \\
\hline K7 & 2000 & $1325 \pm 16$ & 2.3 & $66.3 \%$ \\
\hline K8 & 2000 & $953 \pm 9$ & 1.5 & $47.6 \%$ \\
\hline
\end{tabular}

It is known that ascorbic acid is a very volatile and thermolabile substance and is easily oxidized by oxygen in aqueous solutions to dehydroascorbic acid [30]. A more complex mechanism occurs in dehydrated food systems [31], which include caramel. Therefore, the result is quite satisfactory. Further researches on the stability of ascorbic acid in the food caramel matrix over time will allow us to assess the prospect of caramel production as a prophylactic agent enriched with the required amount of vitamin. 


\section{Antioxidant properties of plant extract}

One of the conditions for using the Folin-Ciocalteu spectrophotometric technique is the need for experimental values of optical density in the range that does not exceed the value of optical density of a standard solution with maximum concentration. That is, in our case, 0.6 for a solution of gallic acid at a concentration of $500 \mu \mathrm{g} / \mathrm{g}$. During the usage for calculations of standard solutions with a concentration above $500 \mu \mathrm{g} / \mathrm{g}$, the graduated graph of the optical density dependence on the concentration of gallic acid becomes nonlinear. During the analyzing objects when it comes to determining the total content of polyphenols, this circumstance should not be logically significant. Indeed, if we have a similar nonlinear dependence for a plant sample, we calculate the standard procedure with allowance for the nonlinearity of the standard curve.

For a more detailed study of this issue, the procedure for defining TPC has been modified. Thus, for a peppermint extract, instead of a single sample weighing $0.1 \mathrm{~g}$ in the standard TPC determination procedure given above, 6 samples with a mass in the range of 0.06-0.35 g were used, and for the chamomile extract, respectively, 3 samples with a mass in the range of $0.15-0.35 \mathrm{~g}$. The results are shown in Figure 2

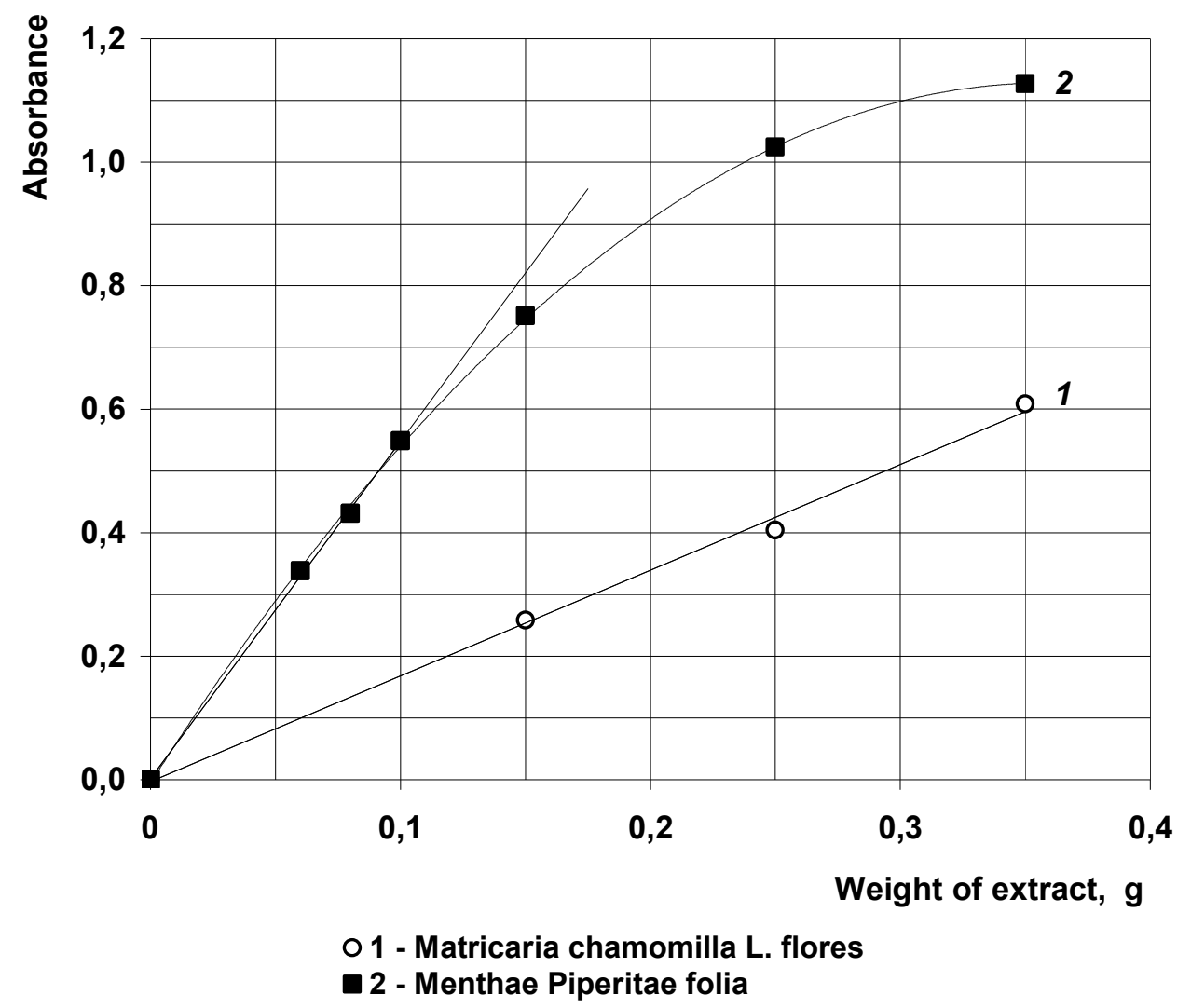

Figure 2. Dependence absorbance of solution from weight of extracts in reaction with Folin-Ciocalteu reagent 
As can be seen from Figure 2, for the chamomile extract, all samples have an optical density in the range of the linearity of the graduated graph to a value of 0.6 . The calculated TPC values for each of the 3 samples were obtained in the range of $15.8-16.9 \mathrm{mg} \mathrm{GAE} / \mathrm{g}$ $\mathrm{SW}$ with an average value of $16.5 \mathrm{mg} \mathrm{GAE} / \mathrm{g} \mathrm{SW}$. Approximation of the obtained linear regression dependence with the inclusion of zero concentration allows obtaining a value of $17,1 \mathrm{mg} \mathrm{GAE} / \mathrm{g} \mathrm{SW}$. This value is more statistically substantiated than the average value of several measurements or even a single one.

In the case of peppermint extract, a nonlinear dependence of optical density on the sample mass after $0.1 \mathrm{~g}$ was obtained. During the calculation of the TPC under the standard procedure, even with the application of a nonlinear graduated graph, we obtain the concentration for the same sample in the range of $31.3-55.0 \mathrm{mg} \mathrm{GAE} / \mathrm{g} \mathrm{SW}$, which is hardly a satisfactory procedure. We have some uncertainty about the size of the TPC sample and its dependence on the size of the sample extract mass in the determination procedure. During the usage of only a linear dependence, i.e. for a peppermint extract, it is 3 of 6 points in the range of $0.06-0.1 \mathrm{~g}$ and it has a TPC value in the range of 52.6-55.0 mg GAE/g SW. During the approximation of the linear regression dependence, we obtain a value of $55.0 \mathrm{mg} \mathrm{GAE} / \mathrm{g} \mathrm{SW}$.

Thus, in order to obtain the correct values of the TPC of plant extracts, we have a modification of the spectrophotometric procedure of determining the total content of polyphenols from the Folin-Ciocalteu reagent, which includes the following:

1. Application of several samples of the test object instead of one with the variation of the ratio of the Folin-Ciocalteu reagent: the reducing agent (polyphenols of a sample), with the verification of the linearity of the analytical signal in the operating range of sample concentrations;

2. The usage of the samples mass in the procedure, whose optical density of solutions does not exceed the maximum optical density of the linear range of the graduated graph for the standard solution;

3. Approximation of the dependence of the linear regression curve (with the inclusion of a zero value) for obtaining statistically substantiated values of TPC.

Table 6 shows us TAC and TPC data for mint and chamomile extracts.

Table 6

Total antioxidant capacity, total polyphenols and flavonoids in Matricaria chamomilla $\mathbf{L}$. flores and Menthae piperitae folia extracts $(n=4, P=0.95)$

\begin{tabular}{|c|c|c|c|c|c|}
\hline \multirow[b]{2}{*}{ Extract } & \multicolumn{2}{|c|}{ TAC } & \multirow{2}{*}{$\begin{array}{c}\text { RSD, } \\
\%\end{array}$} & \multirow{2}{*}{$\begin{array}{l}\text { TPC, } \\
\text { mg GAE/ } \\
\text { g SW }\end{array}$} & \multirow{2}{*}{$\begin{array}{c}\text { RSD } \\
\%\end{array}$} \\
\hline & $\begin{array}{c}\text { mg AAE/ } \\
\text { g SW }\end{array}$ & $\begin{array}{l}\text { mg GAE/ } \\
\text { g SW }\end{array}$ & & & \\
\hline $\begin{array}{c}\text { Menthae } \\
\text { piperitae folia }\end{array}$ & $83.3 \pm 2.4$ & $40.0 \pm 0.8$ & 1.6 & $54.5 \pm 0.8$ & 1.6 \\
\hline $\begin{array}{c}\text { Matricaria } \\
\text { chamomilla } L . \\
\text { flores }\end{array}$ & $48.4 \pm 1.6$ & $23.3 \pm 0.5$ & 2.5 & $17.1 \pm 0.6$ & 1.3 \\
\hline
\end{tabular}

The values of TAC for comparability in the subsequent discussion of the results are presented with the usage of two referential substances - ascorbic and gallic acids. The obtained value of TPC $17.1 \mathrm{mg}$ GAE$/ \mathrm{g}$ SW for aqueous extract $(1: 10 \mathrm{w} / \mathrm{w})$ of Matricaria chamomilla L. corresponds properly to the values of 14.697 and $17.8 \mathrm{mg} \mathrm{GAE} / \mathrm{g}$ 
SW, according to $[14,15]$, respectively. Also, there is satisfactory data comparability on the total antioxidant capacity of TACs aqueous infusions of these plant samples that were obtained also by the method of coulometric titration [32]. The values of TAC, expressed in terms of the amount of electricity without the usage of referential substance, given by the authors are 0.46 and $0.87 \mathrm{kC} / 100 \mathrm{ml}$ infusion, compared to 0.53 and $0.91 \mathrm{kC} / 100 \mathrm{ml}$ obtained in this work for MCF and MPF, respectively.

According to the data on the Table 2, the peppermint extract has high antioxidant properties of $72,1 \%$ of the equivalent of ascorbic acid (mg AAE/g SW) and $71.8 \%$ of the equivalent of gallic acid (GAE/g SW) compared with the same extract of MCF. The content of polyphenols in the extract of MCF is 2.9 times less than in the extract of MPF. This is due to the presence in the mint the content of substances that are stronger antioxidants compared with the chemical composition substances of MCF.

\section{Antioxidant properties of candy caramels}

The results obtained from TAC and TPC for solutions of caramel samples are given in Table 7. According to the data on the Table 7, the antioxidant properties of TAC and TPC for the investigated samples of candy caramel vary in the same way as in the variety of samples of caramel based on maltitol (K1-K4) and in a variety of samples of caramel based on isomaltol (K5-K8). The various mechanisms of oxidative-reduction reactions, simulating the action of radical oxidation are used in these methods of study of antioxidant properties. Thus, in the determination of the TAC, the oxidation reaction with electrogenerated bromine [25], occurs, while in the determination of the TPC, a Folin-Ciocalteau reagent consisting of a mixture of molybdenum tungstic heteropoly compounds in which molybdenum and tungsten, being in a state of oxidation of $6+$, form molybdenum tungstic heteropoly anions with an average state of oxidation of metals from 5 to 6 during the reaction with the reducing agent [33]. Despite the different mechanism of action of the reactions on which these methods of evaluation of antioxidant properties of systems are based, there is a rather high positive correlation between the data obtained (Figure 3). This indicates that the coulometric determination methodology for TACs is sufficiently adequate for these purposes in the studied food systems. This conclusion can be made taking into account the fact that there aren't almost any alternatives in application of the spectrophotometric technique with the Folin-Ciocalteau reagent in relation to the definition of polyphenols as antioxidants.

Antioxidant properties of candy caramel samples $(n=4, P=0.95)$

Table 7

\begin{tabular}{|c|c|c|c|c|c|}
\hline \multirow{2}{*}{$\begin{array}{l}\text { Sample of } \\
\text { candy } \\
\text { caramel }\end{array}$} & \multicolumn{2}{|c|}{ TAC } & \multirow{2}{*}{$\begin{array}{c}\text { RSD, } \\
\%\end{array}$} & \multirow{2}{*}{$\begin{array}{c}\text { TPC, } \\
\text { mg GAE/ } \\
100 \text { g simple }\end{array}$} & \multirow{2}{*}{$\begin{array}{c}\text { RSD, } \\
\%\end{array}$} \\
\hline & $\begin{array}{c}\text { mg AAE/ } \\
100 \text { g simple }\end{array}$ & $\begin{array}{c}\text { mg GAE/ } \\
100 \text { g simple }\end{array}$ & & & \\
\hline K1 & $53 \pm 4$ & $14 \pm 3$ & 2.4 & $97 \pm 5$ & 1.5 \\
\hline $\mathrm{K} 2$ & $178 \pm 2$ & $75 \pm 5$ & 2.6 & $132 \pm 4$ & 1.7 \\
\hline K3 & $1781 \pm 56$ & $603 \pm 10$ & 2.8 & $1041 \pm 10$ & 1.2 \\
\hline K4 & $1680 \pm 64$ & $857 \pm 10$ & 3.1 & $1546 \pm 13$ & 1.5 \\
\hline K5 & $41 \pm 8$ & $8,6 \pm 2$ & 3.6 & $24 \pm 2$ & 1.3 \\
\hline K6 & $365 \pm 9$ & $165 \pm 11$ & 2.5 & $332 \pm 9$ & 1.4 \\
\hline K7 & $1825 \pm 15$ & $872 \pm 15$ & 2.1 & $1340 \pm 23$ & 1.5 \\
\hline K8 & $1874 \pm 16$ & $895 \pm 12$ & 1.9 & $1586 \pm 19$ & 1.6 \\
\hline
\end{tabular}


However, it is necessary to make a significant remark regarding the presented in Table 7 data. The values for K1 and K4 samples are not consistent with the general values of antioxidant capacity and polyphenols content, were selected in italics. Also, for samples $\mathrm{K} 3, \mathrm{~K} 4, \mathrm{~K} 6$ and $\mathrm{K} 7$ the correction is required in the amount of the total content of polyphenols.

Indeed, samples that are made on the basis of fructose and sugar substitutes (K1 and K4 only) have the minimum values of TAC and TPC which are associated with the oxidation of these substances. During the determination of TPC, these substances cannot be attributed to compounds of phenolic nature, and as in the case of reduced sugars, metal ions, ascorbic acid, etc., are considered to be concomitant substances, as indicated in the methods of determination the total content of polyphenols by reaction Folin-Ciocalteu [34]. In the presence of such substances in complex food systems, correction should be made for their presence during the determination of the TPC value of the entire system [23]. Thus, the selected values of the TPCs of the K1 and K4 systems, which actually do not have any polyphenolic nature in, are corrective for the TPC of other systems, given that these systems are included in other as subsystems. The same applies to TAC, given that the components of these samples are not antioxidants.

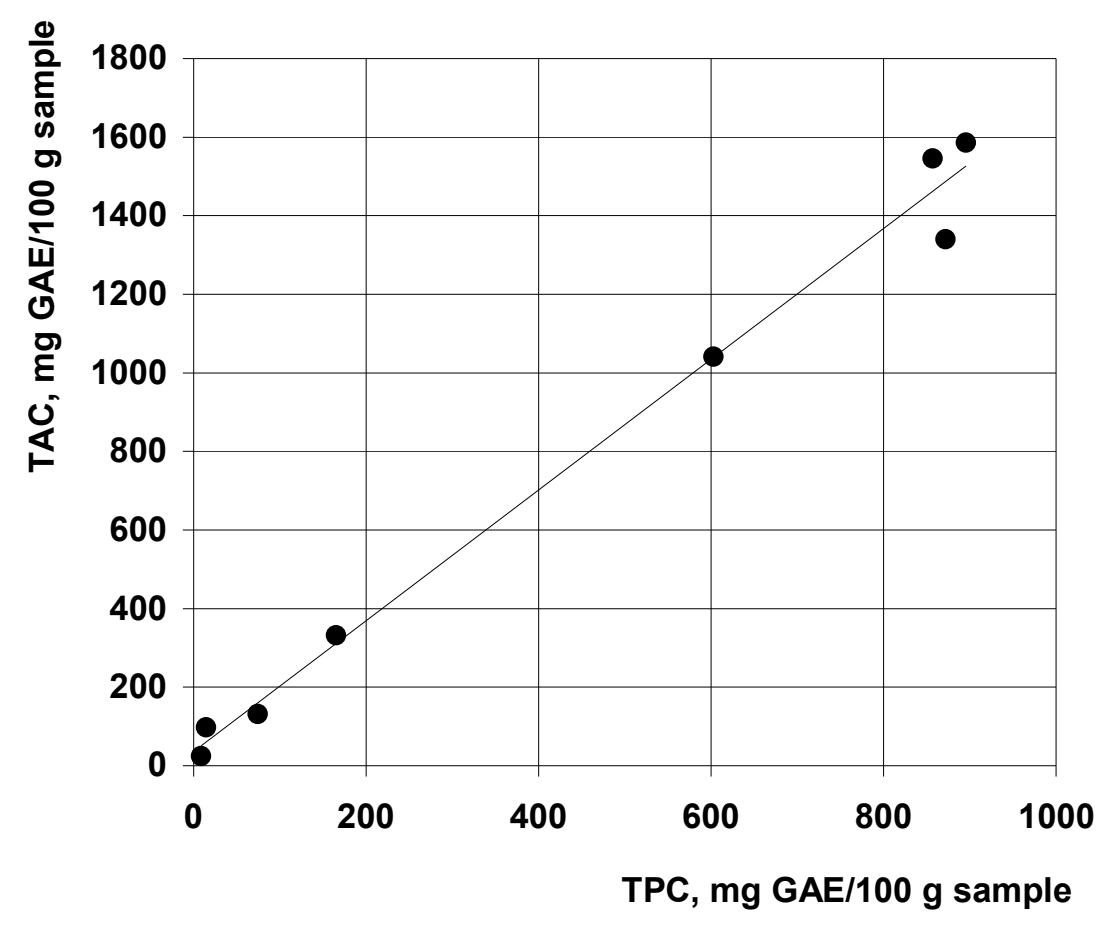

Figure 3. Correlation plots for TAC vs. TPC of candy caramel samples

For caramel samples $\mathrm{K} 3, \mathrm{~K} 4, \mathrm{~K} 7$ and $\mathrm{K} 8$, ascorbic acid which is present in the formulation and makes its contribution to the TAC value as an antioxidant is not a substance of the phenolic nature, which also needs correction for the determined values of TPC caramel. 
Taking into account the foregoing, after making the necessary corrections, we obtain the following values of TPC for samples of the final product 408 and $222 \mathrm{mg} \mathrm{GAE} / 100 \mathrm{~g}$ of the sample for caramel K4 and K8, respectively. These results indicate that despite the higher value of TPC for the peppermint extract and its higher content in the mass of the corresponding caramel, less value was obtained for the content of polyphenols for a caramel sample that is based on this extract compared to chamomile extract samples. An explanation of the obtained patterns in the values of TPC for these samples should be sought in the tread mechanism of the interaction of ascorbic acid with polyphenols; an issue requires more detailed researches than at the level of integral values of TAC and TPC.

For samples of caramel $\mathrm{K} 2$ and $\mathrm{K} 6$, in which there is no ascorbic acid, there is a reverse trend, namely, a higher content of polyphenols in caramel based on mint. This corresponds to the values of TPCs of aqueous extracts, and samples K2 and K6 were enriched by them.

\section{Conclusion}

The following conclusions can be drawn, based on the obtained results:

1. As a result of the study of antioxidant properties of mint and chamomile extracts, it was found that the peppermint extract has a larger antioxidant capacity of 40 versus 23.3 mg GAE/g SW due to the higher amount of polyphenolic compounds. This is evidenced by the higher value of the total content of polyphenolic compounds of 54.5 and $17.1 \mathrm{GAE} / \mathrm{g}$ SW, respectively.

2. Determination of the content of ascorbic acid in samples of candy caramel indicates that, despite the application in the technological process of manufacturing the high temperatures caramel, it was remained from 48 to $66 \%$ of the initial number of ascorbic acid in the samples. This fact is the basis for the application of this technology for the production of vitamin-rich caramel, and its use for prophylactic purposes.

3. Investigation of caramel samples with variation of the recipe components allowed us to determine the correct values of the total content of polyphenolic compounds for two samples of candy caramel: $408 \mathrm{mg} \mathrm{GAE} / 100 \mathrm{~g}$ sample for caramel based on maltitol and chamomile extract and $222 \mathrm{mg}$ GAE/100 g for caramel based on isomaltol and peppermint extract.

4. The procedure of spectrophotometric determination of the total content of polyphenolic compounds in plant objects was modified for the purpose of obtaining statistically substantiated results.

\section{References}

1. Kay O’Donnell, M. K. (Ed.) (2012), Sweeteners and sugar alternatives in food technology (2nd ed.), Oxford, UK: Wiley-Blackwell.

2. Nabors L. O. B. (2004), Alternative sweeteners, Agro Food Industry Hi-Tech, Vol. 15. doi:10.1017/CBO9781107415324.004

3. Zumbé A., Lee A., Storey D. (2001), Polyols in confectionery: the route to sugar-free, reduced sugar and reduced calorie confectionery, British Journal of Nutrition, 85(S1), pp. S31. doi:10.1079/BJN2000260

4. Hartel R. W., von Elbe J. H., Hofberger R. (2018), Confectionery Science and Technology, Cham: Springer International Publishing. doi:10.1007/978-3-319-61742-8 
5. Charles D. J. (2013), Antioxidant properties of spices, herbs and other sources, Springer 4 (Vol. 9781461443). doi:10.1007/978-1-4614-4310-0

6. Marta C.T. Duarte, M. R. (Ed.) (2015), Therapeutic Medicinal Plants: From Lab to the Market, Boca Raton: CRC Press. doi:10.3402/ljm.v7i0.16205

7. Banjarnahor S. D. S., Artanti N. (2014), Antioxidant properties of flavonoids, Medical Journal of Indonesia, 23(4), pp. 239-244. doi:10.13181/mji.v23i4.1015

8. Procházková D., Boušová I., Wilhelmová N. (2011), Antioxidant and prooxidant properties of flavonoids, Fitoterapia, 82(4), pp. 513-523. doi:10.1016/j.fitote.2011.01.018

9. Mazur L., Dorochovich A., Savchuk S. (2016), Use of phyto-tea extracts in the production of candy caramelIn , Scientific achievements of youth-solving problems of human nutrition in the XXI century: materials of 82 international scientific conference of young scientists postgraduates and students, Kiyiv, NUCHT , p. 163.

10. Srivastava J. K., Pandey M., Gupta S. (2009), Chamomile, a novel and selective COX2 inhibitor with anti-inflammatory activity, Life Sciences, 85(19-20), pp. 663-669. doi:10.1016/j.1fs.2009.09.007

11. McKay D. L., Blumberg J. B. (2006), A Review of the bioactivity and potential health benefits of chamomile tea (Matricaria recutita L.), Phytotherapy Research, 20(7), pp. 519-530. doi:10.1002/ptr.1900

12. Munir N., Iqbal A. S., Altaf I., Bashir R., Sharif N., Saleem F., Naz S. (2014), Evaluation of antioxidant and antimicrobial potential of two endangered plant species Atropa belladonna and Matricaria chamomilla., African journal of traditional, complementary, and alternative medicines: AJTCAM, 11(5), pp. 111-7. doi:http://dx.doi.org/10.4314/ajtcam.v11i5.18

13. Sazegar M. R., Banakar A., Bahrami N., Bahrami A., Baghbani M., Nematolahi P., Mottaghi M. (2011), Determination of the Antioxidant Activity and Stability of Chamomile ( Matricaria chamomilla L .) Extract in Sunflower Oil, World Appl. Sci. J., 12(9), pp. 1500-1504.

14. Seddik K., Dalila B., Saliha D., Saliha D., Smain A., Noureddine C., Lekhmici A. (2013), Polyphenols and antioxidant properties of extracts from Mentha pulegium L. and Matricaria chamomilla L., Pharmacognosy Communications, 3(2), pp. 35-40. doi: $10.5530 /$ pc.2013.2.8

15. Harbourne N., Jacquier J. C., O'Riordan D. (2009), Optimisation of the extraction and processing conditions of chamomile (Matricaria chamomilla L.) for incorporation into a beverage, Food Chemistry, 115(1), pp. 15-19. doi:10.1016/j.foodchem.2008.11.044

16. Noue T. I., Ugimoto Y. S., Asuda H. M., Amei C. K. (2002), Antiallergic Effect of Flavonoid Glycosides Obtained from Mentha piperita L ., Biol. Pharm. Bull., 25(2), pp. 256-259.

17. Taher Y. A. (2012), Antinociceptive activity of Mentha piperita leaf aqueous extract in mice Yousef, Libyan Journal of Medicine, 1, pp. 7-11. doi:10.3402/ljm.v7i0.16205

18. Barbalho S. M. (2017), Properties of mentha piperita : a brief review, World Journal of Pharmaceutical and Medical Research, 3(1), pp. 309-313.

19. Meenatchisundaram S., Parameswari G., Sunny D., Brinda M., Subbraj T. (2009), Pharmacological Activities of Mentha piperita- Mini Review, Ethnobotanical Leaflets, 13, pp. 213-215.

20. Assessment report on Mentha x Piperita L.; Folium; EMEA/HMPC/193910/2007 (2008), London.

21. Neves J. M., Gomes L. R., Moutinho C., Matos C., Neves J. M., Teixeira D. M. (2013), Antispasmodic activity of aqueous extracts from Mentha x piperita native from Trás- 
osMontes region ( Portugal ), International Journal of Indigenous Medicinal Plants, 29(1), pp. 1167-1174.

22. Parsons E. (Ed.) (2016), Ascorbic Acid: Properties, Synthesis and Applications, Nova Science Publishers.

23. Singleton V. L., Orthofer R., Lamuela-Raventós R. M. (1999), [14] Analysis of total phenols and other oxidation substrates and antioxidants by means of folin-ciocalteu reagentIn , Methods in Enzymology (pp. 152-178). doi:10.1016/S0076-6879(99)990171

24. AOAC Official Methods of Analyisis of AOAC International (2000), (17th editi.), Gaithersburg: MD.

25. Ziyatdinova G. K., Nizamova A. M., Budnikov G. K. (2010), Galvanostatic coulometry in the analysis of natural polyphenols and its use in pharmacy, Journal of Analytical Chemistry, 65(11), pp. 1176-1180. doi:10.1134/S1061934810110146

26. Gubskyi S., Nikitin S., Evlash V., Nemirich O. (2015), Iodine content determination in dried talli of laminaria by galvanostatic coulometry, Ukrainian Food Journal, 4(2), pp. 320-327. doi:10.13140/RG.2.1.4488.6485

27. Gubsky S., Artamonova M., Shmatchenko N., Piliugina I., Aksonova E. (2016), Determination of total antioxidant capacity in marmalade and marshmallow, EasternEuropean Journal of Enterprise Technologies, 4(11(82)), pp. 43. doi:10.15587/17294061.2016.73546

28. Evlash V., Gubsky S., Aksonova E., et al. (2016), Determination of ascorbic acid amount in gelatin aqueous solutions by galvanostatic coulometry using electrogenerated bromine, Industrial Technology and Engineering, 18(1), pp. 22-31.

29. Singleton V. L., Rossi J. A. (1965), Colorimetry of Total Phenolics with Phosphomolybdic-Phosphotungstic Acid Reagents, American Journal of Enology and Viticulture, 16(3), pp. 144 LP-158.

30. Yuan J.-P., \& Chen F. (1998), Degradation of Ascorbic Acid in Aqueous Solution, Journal of Agricultural and Food Chemistry, 46(12), pp. 5078-5082. doi: $10.1021 / \mathrm{j} 99805404$

31. Kirk J., Dennison D., Kokoczka P., Heldman D. (1977), Degradation of ascorbic acid in a dehydrated food system, Journal of Food Science, 42(5), pp. 1274-1279. doi:10.1111/j.1365-2621.1977.tb14477.x

32. Lapin A. A., Borisenkov M. F., Karmanov A. P., Berdnik I. V., Kocheva L. S., Musin R. Z., Magdeev I. M. (2007), Antioxidant properties of vegetable products origins, Khimija Rastitel'nogo Syr'ja, 2, pp. 79-83 (in Russian).

33. Agbor G. A., Vinson J. A., Donnelly P. E. (2014), Folin-Ciocalteau Reagent for Polyphenolic Assay Description of Folin Ciocalteau Reagent, International Journal of Food Science Nutrition and Dietetics, 3(38), pp. 147-156. doi:10.19070/2326-33501400028

34. Wrolstad R. E., Acree T. E., et al. (Eds.) (2003), Current Protocols in Food Analytical Chemistry, John Wiley \& Sons, Inc. 